\title{
Vozes sem eco entoadas no Nordeste do Brasil: construtos de resistência à degradação ambiental
}

\author{
Echoless voices from Brazil's Northeast: constructs of resistance against environmental \\ degradation
}

Augusto Marcos Carvalho de Sena ${ }^{1}$

Fátima Regina Ney Matos ${ }^{2}$

\begin{abstract}
Resumo
O artigo enaltece as vozes contra a degradação ambiental, com foco na fauna, flora e ambientes naturais circunscritos, usando a poesia contida em obras da música popular brasileira nordestina. Assume-se que tal poesia pode ser usada como denúncia do grave problema de degradação ambiental que ora ocorre no Brasil, e que movimentos ambientalistas podem e devem usá-la em suas atuações ativistas. O estudo usou a riqueza poético-ecológica contida em cinco músicas: Saga da Amazônia, Canção da Floresta, Matança, Água e Natureza. A evidência mostrou que há forte conteúdo de denúncia nas músicas e, como conclusão, sugere-se que as vozes devem se revestir de importância ímpar para preservação da biodiversidade e para movimentos de luta ambientalista no Brasil.
\end{abstract}

Palavras-Chave: Degradação da fauna e flora. Desmatamento florestal. Vozes da resistência.

\begin{abstract}
This article emphasizes the voices against environmental degradation, focusing on flora, fauna and natural environments, using the poetry embodied in the lyrics of music from the northeastern region of Brazil. It is assumed that such poetry could be viewed as the musicians from this region denouncing the serious problem related to environmental depletion in Brazil and, therefore, that pro-ecological movements might use it in their activist actions. The study used the ecologically rich contents of five songs: Saga of Amazonia, Song of the Forest, Wood Slaughter, Water and Nature. The evidence showed that there is a strong denouncing content in the lyrics and, in conclusion, it is suggested that the voices of resistance must be considered as of crucial importance to the preservation of biodiversity and environmental activist movements in Brazil.
\end{abstract}

Keywords: Degradation of fauna and flora. Deforestation. Voices of resistance.

\footnotetext{
Texto submetido em 30 de julho de 2012 e aceito para publicação em 09 de agosto de 2012.

${ }^{1}$ Ph.D em Economia pela University of New Hampshire - USA; Coordenador e professor titular do Programa de Pós-Graduação em Administração de Empresas (PPGA) da Universidade de Fortaleza (UNIFOR). Endereço: Avenida Washington Soares, 1321, CEP 60811-341, Fortaleza - CE, Brasil. E-mail amsena@unifor.br

2 Doutora em Administração pela Universidade Federal de Pernambuco - UFPE; Professora adjunta do Programa de Pós-Graduação em Administração de Empresas (PPGA) da Universidade de Fortaleza (UNIFOR). Endereço: Avenida Washington Soares, 1321, CEP 60811-341, Fortaleza - CE, Brasil. E-mail fneymatos@globo.com, fneymatos@unifor.br
} 


\section{Introdução}

Atualmente movimentos de resistência a ações humanas devastadoras do meio ambiente são variados, seja na forma de organização da reação, se sociocomunitário, governamental, não governamental ou mesmo empresarial, seja no aspecto da dimensão geográfica, se local, regional, nacional ou até mesmo mundial. Este artigo enaltece as vozes sem eco contra a degradação ambiental, com foco na fauna, flora e ambientes naturais circunscritos, usando a poesia contida em obras da Música Popular Brasileira do Nordeste (MPB$\mathrm{NE}$ ). Como forma de dar suporte teórico à adjetivação sem eco, assim como ao spectrum da atuação concreta de movimentos sociais ambientalistas, as vozes da resistência são contextualizadas utilizando-se as contribuições de Escobar (1992, 1995 e 1998), Gasper (1996), Edwards (1989) e Dallmayr (1996), onde dimensões políticas, sociais, ambientais e culturais se entrelaçam, dando conformidade específica às práticas de reação dos atores no mundo real. Tais dimensões são analisadas enfocando-se a ecologia política como a concepção teórica de referência.

O trabalho assume que a poesia veiculada nas músicas de artistas que trafegam na MPB-NE pode ser usada por movimentos sociais como importante elemento disseminador do esforço de luta, tanto contra a degradação do meio ambiente, em particular, como das condições humanas de vida, em geral. Na particularidade, as vozes podem ser interpretadas como denúncia crítica do artista compositor-cantadorletrista nordestino em relação ao grave problema da degradação da fauna, flora e ambientes naturais no Brasil, e os movimentos sociais podem e devem usá-las em suas atuações ambientalistas concretas. A arte pode, assim, ser considerada como importante instrumento de expressão da cultura de resistência. O objetivo buscado no artigo é evidenciar as fontes diretas de manifestação desta relevante riqueza sociocultural, aqui concebida como vozes da resistência à degradação ambiental.

Em sintonia com o objetivo aqui buscado, ressalte-se que o Musicians United to Sustain the Environment Músicos Unidos em Suporte ao Meio Ambiente (MUSE) - é atualmente uma importante organização não governamental que atua em defesa do meio ambiente nos Estados Unidos, usando músicos e músicas, dando apoio a movimentos sociais de resistência à degradação ambiental na linhagem participativa do tipo grassroots. Apesar de, no Brasil, ainda não existir tal arranjo de forma institucionalizada, há na atuação concreta de movimentos sociais de preservação ambiental e na poesia ecológica das obras da MPB-NE fortes componentes para se conjecturar tal possibilidade, principalmente tendo-se em conta o processo de massificação consumista alienígena que avassala a música popular brasileira em geral e, em particular, a regional. Assim, contribuição paralela ao uso da poesia contida na MPB-NE como construto de resistência à degradação ambiental, conjecturado como incorporável à atuação de movimentos sociais ambientalistas, no presente artigo vislumbra-se também leitura crítico-poético-harmoniosa de resistência à intromissão de elemento cultural impositivo. Quiçá as vozes sem eco, em futuro vindouro, ecoarão.

A metodologia contempla análise documental utilizando o material contido nos encartes originais de cada obra artística, isto é, far-se-á uso dos encartes dos discos originais onde estão contidas as letras e alguns comentários sobre as obras. A estruturação metodológica dará ênfase aos construtos de resistência observando-se criteriosamente três frentes de reação: à degradação da fauna e flora, ao desmatamento florestal e à degradação de paisagens naturais circunscritas. Metodologicamente, esforço é concentrado na busca de atrelar tais construtos de resistência, contidos nas letras das músicas, ao aparato teórico da ecologia política.

A primeira seção do artigo apresenta parte da literatura sobre massificação sociocultural alienígena, conduzida por padrões impositivos advindos do modo de consumo do mundo ocidental moderno. Nesse ínterim, alusão é feita aos movimentos sociais de resistência à implantação de tais moldes ocidentais de comportamento, tanto na América Latina como em várias partes do mundo, principalmente a partir dos anos 1980s, enfocando a importante contribuição da abordagem participativa de linhagem grassroots, como em Escobar (1992; 1995), Gasper (1996), Edwards (1989) e Dallmayr (1996).

$\mathrm{Na}$ segunda seção usa-se a literatura sobre ecologia política, ênfase sendo dada aos aspectos de interrelacionamento entre as dimensões ambientais, culturais e políticas do processo específico de atuação de movimentos sociais ambientalistas. Como antecipado por Peterson (2000), todo processo ecológico envolve 
o comportamento humano, e a ecologia política, portanto, traduz-se em suporte robusto para a análise integrada da dinâmica de defesa socioambiental. Nessa mesma vertente, Escobar (1998) analisa a conservação da biodiversidade usando as dimensões da ecologia política e suas inter-relações com movimentos sociais. Tal arcabouço teórico servirá de suporte para análise a ser desenvolvida na terceira seção do artigo, onde se evidencia a riqueza ecológica da poesia contida nos cantos sem eco de artistas da MPB-NE, e se argumenta como tal riqueza pode e deve ser utilizada como instrumento disseminador da luta de resistência à degradação ambiental.

Conjecturas sobre problemas relativos à interação teoria-prática presentes no estudo, assim como perspectivas abertas a trabalhos futuros sobre o tema são apresentadas na conclusão. Apesar de explicitamente não existir movimentos socioculturais localizados, focados e concentrados, em relação à resistência à degradação ambiental e encampados por compositores-cantadores-letristas do nordeste do Brasil, aos moldes da ONG MUSE nos Estados Unidos, o conteúdo de resistência dessas vozes é imenso e de grande potencial de penetração na esfera sociopolítica. Também, trabalhos alternativos, por exemplo, sobre vozes da resistência à degradação das condições de vida do homem do campo, podem ser conduzidos usando-se metodologia idêntica a aqui utilizada.

\section{Resistência ao Globalocentrismo e a Abordagem Participativa Grassroots}

Nesta seção, alusão é feita à parte da literatura que trata da crítica ao tipo de intervenção a que sociedades menos desenvolvidas se sujeitam, no mais das vezes, imposto por padrões socioculturais completamente alheios aos das comunidades locais. Além disso, faz-se referência aos movimentos sociais de resistência à implantação de moldes ocidentais de comportamento, tanto na América Latina como em várias partes do mundo, principalmente a partir dos anos 1980s, enfocando as importantes contribuições de Escobar (1992, 1995), Gasper (1996), Edwards (1989) e Dallmayr (1996). No contexto do objetivo central do artigo, tais contribuições serão usadas como suporte à adjetivação sem eco dada às vozes da resistência dos compositores-cantadores-letristas da MPB-NE, visto que contemplam os construtos de resistência ao caráter impositivo de culturas alienígenas, sempre presentes na atuação específica do interventor externo.

Escobar (1995) desenvolve análise crítica em relação ao modo como países do terceiro mundo têm sofrido intervenção, sob a retratação de especialistas externos, quando da implantação e implementação de programas de desenvolvimento, em geral, via imposição de moldes ocidentais (euro-americanos) de comportamento e consumo. Em referência a esse tipo de intervenção, Escobar (1995, p. 13) diz:

O desenvolvimento tem se apoiado em um único sistema de conhecimento, isto é, o do tipo ocidental moderno. A dominância desse sistema de conhecimento tem ditado a desqualificação e discriminação de sistemas de conhecimento não ocidentais [...], pesquisadores e ativistas deveriam encontrar racionalidades alternativas para guiar ações sociais de forma muito distinta dos modos reducionistas e economicistas de pensamento (tradução nossa).

Esta citação traz forte mensagem em prol da luta de resistência, incluindo a atuação de pesquisadores e ativistas (movimentos sociais) de países do terceiro mundo, à imposição de verdades advindas de fora para dentro. Como expresso, a dominação alienígena tenta marginalizar e desqualificar sistemas de conhecimento não ocidentais.

No Brasil, a cultura local, em geral, e a música regional, em particular, têm enfrentado tal tentativa de marginalização e desqualificação. Note também que o autor aponta para perspectiva alentadora, quando menciona que racionalidades alternativas podem ser importantes norteadores de ações sociais, como a racionalidade seguida pelo presente estudo, ao colocar a poesia das músicas da MPB-NE como instrumento de luta ambientalista a ser usado por movimentos sociais ativistas contra a degradação da fauna, flora e ambientes naturais no Brasil. 
Em crítica similar, Edwards (1989) se refere à irrelevância de ações intervencionistas por elemento estranho, afirmando que nelas as pessoas são tratadas como objetos ao invés de sujeitos de seus próprios anseios. Como afirma Edwards (1989, p. 120): "Uma consequência adicional da visão dominante é a desvalorização do conhecimento nativo (que cresce diretamente da experiência do povo pobre) na busca por soluções aos problemas com que nos defrontamos [...]. O que é preciso é uma 'ciência do povo' que use conhecimento local para explorar soluções locais para problemas locais” (tradução nossa).

Já Gasper (1996) aponta para uma direção ética no processo de intervencionismo, onde identidade e diferenças culturais devem ser consideradas em conjunto com diversidade, conflito e mudanças dentro de cada sociedade, arranjo esse que os processos tradicionais de intervenção não contemplam. Ele sugere uma contextualização de crença comunitária onde moralidade advenha de normas comunitárias internas, afirmando que éticas universalistas sejam flexibilizadas de modo a inserir tradições e escolhas locais.

Nesse contexto, a sugestão de inclusão de tradição e escolha locais no processo de desenvolvimento ético de uma sociedade nos remonta à perspectiva alentadora de inserção da cultura e da música na dinâmica de mudança social de certo local.

Escobar (1992) se refere à emergência de um grupo de pesquisadores do terceiro mundo, cuja agenda de pesquisa contempla importantes refinamentos para o desmantelamento da prática de intervencionismo alienígena. Cada vez mais presente hoje, em países pobres, há estudos cujo interesse é explícito no conhecimento e cultura locais, com atuação destacada de movimentos localizados e plurais na linhagem participativa do tipo grassroots. Esse autor fundamenta sua crítica radical ao discurso de dominação, como forma hegemônica de representação do terceiro mundo, colocando a resistência dos movimentos sociais grassroots como alternativa política de resposta da comunidade local.

A concepção da atuação de movimentos sociais por ativistas em diferentes partes do terceiro mundo, como posto por Escobar (1992), tem assim sua essência ligada à luta de resistência de atores locais contra a imposição de modos de concepção de comportamento externo, da mesma forma que Dallmayr (1996) retrata a resistência das vozes vindas do subcontinente indiano, afirmando que o Center for the Study of Developing Societies em Delhi, na Índia, (Centro de Estudo de Sociedades em Desenvolvimento) é força viva congregadora de toda uma variedade de vozes de repúdio ao globalocentrismo.

Em sintonia com o objetivo aqui perseguido, e em relação à adjetivação sem eco das vozes da resistência à degradação ambiental, pode-se dizer que a força ativista dessa forma de expressão poético-cultural do nordeste é bastante restrita, em decorrência da massificação consumista ditada por padrões externos à cultura local, e que merece ser analisada criticamente. À luz das concepções teóricas aqui analisadas, poder-se-ia até conjecturar atuação mais consciente por parte de movimentos sociais, por exemplo, através de ONGs nordestinas de linhagem cultural.

\section{Ecologia Política, Biodiversidade e Movimentos Sociais}

Peterson (2000) afirma que todo processo ecológico envolve o comportamento humano e a ecologia política, portanto, traduz-se em importante suporte para a análise integrada da dinâmica socioambiental.

Escobar (1998), alternativamente, analisa a conservação da biodiversidade usando as dimensões da ecologia política e suas inter-relações com movimentos sociais. Segundo ele, a conservação da biodiversidade deve ser concebida como um construto permeado por cultura e natureza, contemplando uma rede de interações, de localidades e atores, através dos quais, conceitos, políticas, culturas e ecologias são contestados e negociados. Relacionando tal arranjo à prática de resistência à degradação social e biofísica da região do Pacífico da Colômbia, conduzida pela comunidade negra dessa região, Escobar (1998, p. 75) coloca:

O movimento social de comunidades negras da região do pacífico colombiano, por exemplo, possibilita uma política cultural que é significativamente mediada por preocupações ecológicas, incluindo biodiversidade. Apesar de forças negativas em oposição 
a ele, e na presença de certas conjecturas culturais e ecológicas favoráveis, é possível pensar que esse movimento deve representar uma defesa real do espaço social e biofísico da região. O movimento social de comunidades negras pode ser assim descrito como um adereço cultural e ecológico ligado ao território, e mesmo uma tentativa de propiciar a existência de novos territórios. Apesar de sua precariedade, sua articulação vinculando cultura, natureza e desenvolvimento constitui um suporte alternativo de ecologia política para discussões sobre a biodiversidade. O movimento pode ser visto como uma tentativa de mostrar que vida social, trabalho, natureza e cultura podem ser organizados diferentemente (tradução nossa).

Nessa perspectiva, vislumbra-se, no presente artigo, a possibilidade de movimentos sociais de natureza ambientalista no Brasil contemplar dimensões envolvendo apego cultural e ecológico a determinado território. Na citação, ressalta-se que a articulação entre cultura, natureza e desenvolvimento local é concebida como suporte alternativo da ecologia política para lidar com discussões sobre conservação da biodiversidade, incorporando aspectos sociopolíticos e ecológicos na prática ativista do movimento social de resistência específico.

Em referência aos tipos de atores que poderiam engrossar fileiras na contextualização da atuação participativa sugerida, Escobar (1998, p. 76) instrui que "[...] Nos espaços de encontro e debate propiciados pelo elo da biodiversidade poderiam ser encontradas maneiras para acadêmicos, cientistas, ONGs e intelectuais (incluindo artistas) refletirem seriamente sobre moldes alternativos e dar a eles suporte que, com maior ou menor grau de clareza e sofisticação, lapidem os movimentos sociais do Terceiro Mundo" (tradução nossa).

É exatamente nesse contexto que, na seção seguinte, a riqueza poético-ecológica da MPB-NE será apresentada com o intuito de servir de instrumento de luta à resistência contra a degradação ambiental no Brasil, podendo assim fazer parte de táticas de atuação da resistência.

\section{Vozes Sem Eco da MPB-NE: Construtos de Resistência à Degradação Ambiental}

Nesta seção apresenta-se a evidência das vozes da resistência. A riqueza ecológica da poesia contida nas músicas de artistas da MPB-NE é apresentada, e argumenta-se que tal riqueza pode ser usada como importante instrumento disseminador do ideário de resistência por movimentos ambientalistas. A análise dos construtos de resistência é conduzida observando-se três linhas de reação: à degradação da fauna e flora, ao desmatamento florestal e à degradação de ambientes naturais circunscritos. Ressalte-se o fato de que somente cinco músicas são analisadas. Todos os autores ditos pertencerem à classificação MPB-NE são nascidos na região. Vários outros artistas regionalistas, que também incluem em suas obras músicas de conteúdo de resistência à degradação ambiental, podem ser citados. Por exemplo, os compositores-cantadores mineiros Dércio Marques e Doroty Marques, em Cantos da Mata Atlântica, disponibilizam rico material poéticoecológico em defesa da mata atlântica. Também o famoso pernambucano de Exu, Luiz Gonzaga, em seu Xote Ecológico, denuncia explicitamente os efeitos danosos da poluição.

\section{Desmatamento Florestal: Tributo à Fauna, Flora e Ambientes Naturais}

A primeira obra, Saga da Amazônia, da autoria de Farias (1984), trata da devastação que ora se impõe à floresta amazônica. Em relação a ambientes naturais circunscritos vê-se que imensa floresta, mata verde, rios puxando águas, igarapés e riachos permeiam a riqueza poética do canto. A fauna florestal está presente em abundância, com toda a diversidade de espécies de diferentes habitats: papagaios, periquitos, peixes singrando rios, curumins, juruparis, uirapurus. E a ordem dada à preguiça, ao tamanduá, à tartaruga e ao pé- 
ligeiro é de forte caráter denunciativo da presença de elemento estranho na região amazônica. Com menor intensidade, a flora se mostra em flores e frutos, mas presente está em toda a circunscrição de diferentes ambientes naturais da floresta. Fragmentos do canto, relativos aos três aspectos enfatizados, são abaixo transcritos.

\section{Saga_da_Amazônia - Autor: Vital Farias (PB)}

Era uma vez na Amazônia, a mais bonita floresta. Mata verde, céu azul, a mais imensa floresta ... E os rios puxando as águas. Papagaios, periquitos, cuidavam de suas cores. Os peixes singrando os rios, curumins cheios de amores. Sorria o jurupari, uirapuru seu porvir era: fauna, flora, frutos e flores. Toda mata tem caipora para a mata vigiar. Veio caipora de fora para a mata definhar ... o dragão cortar madeira e toda mata_derrubar: se a floresta, meu amigo, tivesse pé prá andar, eu garanto meu amigo, com o perigo não tinha ficado lá. O que se corta em segundos gasta tempo prá vingar. $\mathrm{E}$ o fruto que dá no cacho pra gente se alimentar?? Depois tem o passarinho, tem o ninho, tem o ar, igarapé, rio abaixo, tem riacho e esse rio que é um mar ... Mas o dragão continua a floresta devorar. E quem habita essa mata pra onde vai se mudar??? Corre ... preguiça, tamanduá, tartaruga, pé-ligeiro, corre, corre ... Foi então que um violeiro chegando na região ficou tão penalizado e escreveu esta canção. E talvez desesperado com tanta devastação, pegou a primeira estrada sem rumo, sem direção ... sumiu levando essa mágoa dentro do seu coração ... Pra defender o que ainda resta, sem rodeio, sem aresta, era uma vez uma floresta na linha do Equador.

A denúncia é contundente e explicitamente se observa a existência da intromissão alienígena: o caiporadragão de fora. Relacionando esse canto ao construto da ecologia política antecipado por Escobar (1998), pode-se dizer que a interação entre cultura e ecologia vem atrelada à defesa do território específico: a floresta amazônica. Se essa voz de resistência for um dia ecoada, a devastação dessa floresta, com certeza, cessará.

O violeiro-cantador, Dias (2004), em seu canto Canção da Floresta, alerta o mundo contra o monstro da devastação florestal, denunciando feridas que o próprio homem tem feito no coração da mata. Diz ele sabiamente: "Fauna e flora valem mais do valor que o ouro tem [...]. A natureza é selvagem [...]. Ela é a mãe dos seres vivos [...]. Floresta é palco de ave, museu de sonho e de flor". As presenças mais marcantes são a flora, quando citadas, árvores ao chão, plantas a serem regadas, cedros que tombam e flores obras de museu, e os ambientes naturais circunscritos, como matas que queimam, florestas que morrem, pomar a serem feitos e rios a serem limpos. Partes do canto referentes a esses dois aspectos são abaixo transcritos.

\section{Canção da Floresta - Autor: Sebastião Dias (RN)}

Tombam árvores [...], queimam matas, ninguém vê que o futuro está perdido [...] alertem o mundo pra floresta não morrer. Devastação é um monstro que a natureza atropela. Essas manchas de queimadas, que hoje vemos sobre ela, são feridas que os homens fizeram no corpo dela. Use as mãos, mude uma planta, regue o chão, faça um pomar. Ouça a voz do passarinho, a floresta quer chorar. Quando os cedros vão tombando dão até a impressão, que os estalos são gemidos implorando compaixão [...]. O homem talvez procure pôr a culpa no machado [...] 'e por quem foi amolado?' Fauna e flora valem mais do valor que o ouro tem. A natureza é selvagem, mas não ofende ninguém. Ela é a mãe dos seres vivos, precisa viver também [...] limpem os rios [...] Floresta é palco de ave, museu de sonho e de flor.

Matança, música e letra de autoria de Jatobá (1981), encerra riquíssimo conteúdo poético do retrato biodiverso de espécies da flora de duas matas brasileiras: a amazônica e a atlântica. A denúncia contra a matança envolve citação de 39 tipos de madeira, talvez a obra musical que no mundo mais contenha espécies da flora. Os movimentos das quedas são harmoniosamente contrapontuados à rítmica das vozes: pinheiro balança, matas vão matar, imburana de sono morrer, cedro: destino é virar mesa, jacarandá: destinos são virar porta e ter vida eterna no dicionário. Tal riqueza floral está hoje sob a mira devastadora do elemento 
invasor. Em relação à voz de resistência contida na obra, a denúncia é explícita, e o alerta é dado, pois quando chegar a hora, antecipada em Postel (1994), já será tarde demais.

\section{Matança - Autor: Jatobá (BA)}

Cipó caboclo tá subindo na virola. Chegou a hora do pinheiro balançar, sentir o cheiro do mato da imburana, descansar, morrer de sono na sombra da barriguda. De nada vale tanto esforço do meu canto, pra nosso espanto tanta mata haja vão matar. Tal mata atlântica e a próxima amazônica, arvoredos seculares impossível replantar. Que triste sina teve cedro nosso primo. Desde de menino que eu nem gosto de falar. Depois de tanto sofrimento seu destino virou tamborete, mesa, cadeira, balcão de bar. Quem por acaso ouviu falar da sucupira. Parece até mentira que o jacarandá antes de virar poltrona, porta, armário, morar no dicionário, vida eterna milenar. Quem hoje é vivo corre perigo e os inimigos do verde, da sombra. $\mathrm{O}$ ar que se respira e a clorofila das matas virgens destruídas bom lembrar, que quando chegar a hora, é certo que não demora, não chama nossa senhora, só quem pode nos salvar é: caviúna, cerejeira, baraúna, imbuia, pau-d'arco, solva, juazeiro e jatobá, gonçaloalves, paraíba, itaúba, louro, ipê, paracaúba, peroba, massaranduba, carvalho, mogno, canela, imbuzeiro, catuaba, janaúba, aroeira, araribá, pau-ferro, anjico, amargoso, gameleira, andiroba, copaíba, pau-brasil, jequitibá.

As três obras analisadas contemplam, em essência, o desmatamento que ora impera em parte substancial das florestas, em particular, da amazônica e da mata atlântica no Brasil. O caráter de denúncia permeia toda a poesia e insere o que Escobar (1998) chama de inclusão progressiva de resistência se referindo a atuações concretas de movimentos sociais. Por meio da mensagem de denúncia ambiental disseminada por tais vozes, a preservação e apropriação da biodiversidade podem ser tratadas de maneira ímpar, isto é, levando-se em consideração a defesa da cultura e do território que circunscreve os ambientes florestais das duas matas. Referindo-se ao suporte teórico que a ecologia política pode se prestar, em relação ao papel de contemplar a conservação e apropriação da biodiversidade e a atuação de movimentos sociais ambientalistas, Escobar (1998, p. 54) afirma:

Por meio da política cultural que eles possibilitam, os movimentos sociais nos adiantam uma abordagem única para a conservação e apropriação da biodiversidade. Essa abordagem é compactada em termos de diferença cultural, defesa territorial, e alguma medida de autonomia social e política. Ao aderir a uma visão de biodiversidade ligada à defesa cultural e territorial, esses movimentos sociais articulam um suporte alternativo de ecologia política (tradução nossa).

A contextualização em relação às concepções teóricas, usadas nas seções 1 e 2, deve ser feita atentando-se para o fato de que o estudo aqui desenvolvido não contempla a atuação dos movimentos sociais de resistência à degradação ambiental per si, mas sim como se poderia vislumbrar a utilização de um importante meio de veiculação do ideário de luta: as vozes sem eco da poesia contida em obras da MPB-NE do Brasil. Em sintonia fina com o objetivo central do estudo, a contribuição aqui sugerida é que vozes, como as entoadas na poesia das músicas aqui analisadas, sejam, mais e mais, interpretadas e introduzidas na prática de atuação de movimentos sociais que resistem à degradação da fauna, flora e ambientes naturais no Brasil. É notório e explícito o caráter denunciativo contido na riqueza poética das três músicas acima analisadas, principalmente no que diz respeito ao desmatamento florestal.

\section{Retrato da Biodiversidade da Fauna e Degradação de Recursos Naturais}

A música Água, da autoria de Avelino e Jatobá (1981), enaltece a importância desse recurso natural (exaurível?) no contexto de alerta à possibilidade de manutenção da sustentabilidade de ecossistemas. Se sustento eterno de matas, se centro da vitalidade do universo, e até se responsável por existência de vida em 
Marte, a voz entoa resistência sutil em relação aos descuidos da ação humana em relação ao uso da água, recurso natural de tão preciosa valia. Em relação a ambientes naturais circunscritos, a grota e a mata recebem especial atenção em virtude da imagem poético-paisagística usada no canto.

\section{Água - Autores: Eugênio Avelino [Xangai] (BA) e Jatobá (BA)}

A grota inteira tá chorando de saudade da umidade que fecunda a terra seca. Vital retalho do céu que manda pro solo, divino orvalho, gozo que nos eterniza. Intimidade que pertence à natureza [...] Sustento eterno das matas, do mar o vento. Centro da vitalidade do universo. Verso e reverso que reveste a natureza. Está presente na terra, em toda parte. Na arte farta de tanta imagem poética que alimenta a filosófica estética. Clara, cristalina, límpida e forte. É responsável pela vida ou morte em marte. Se faltar aqui na terra tem tragédia, catastrófica será se vem de sobra. E a nossa ignorância será mágoa, mas a nossa inteligência será trégua. Quando sólidos e sós seremos água.

A voz contida em Natureza, da autoria dos cantadores Villanova e Avelino (1984), não entoa explicitamente qualquer tipo de resistência, mas enaltece a biodiversidade da fauna terrestre e a riqueza ecológica presente em diferentes habitats naturais. Assim, o peixe-elétrico eletrocuta com fios da natureza; a tartaruga chega aos quatrocentos anos com certeza; o mundo encantado da passarada de majestosa cor; o impala, a zebra, o leão, o tigre-de-bengala e o macaco; a tromba prênsil do elefante; a saliva incolor do ruminante; o morcego, a formiga e a aranha; e a feiúra real do caboré; e a cobra que mister é aplicar o seu veneno, de uma vez mata trinta se puder, mas tudo é obra divina da natureza.

Em referência à luta de preservação de ecossistemas por movimentos ativistas de proteção ambiental no Brasil, e dentro da contextualização de apropriação e preservação da biodiversidade presente em Escobar (1998), a obra Natureza dispõe de elementos importantes relativos à variedade de espécies e ambientes naturais circunscritos.

\section{Natureza - Autores: Ivanildo Villanova (PE) e Eugênio Avelino [Xangai] (BA)}

[...] O poroquê ou peixe-elétrico é um tipo genuíno, habitante dos rios e águas pretas. Com ele possui certas plaquetas que o dotam de um mecanismo fino. E com tal cartilagem esse ladino faz contato com muita ligeireza. Quem tocá-lo padece de surpresa, descarga mortífera absoluta, sua autovoltagem eletrocuta com os fios da santa natureza. A tartaruga gostosa, feia e mansa, habitante dos rios e oceanos. Chegar aos quatrocentos anos para ela é rotina, é confiança. Guarda ovos na areia e nem se cansa de por eles zelar como defesa [...]. O canário é pássaro cantor, diferente de garça e pelicano, papagaio, arara e tucano, todos eles com majestosa cor. O gavião é um tipo caçador e columbiforme é a bruguesa. $\mathrm{O}$ aquático flamingo é da represa, a águia rapace agigantada, eis o mundo das aves, a passarada, quanto é grande, poderosa e bela a natureza. A gazela, o antílope e o impala, a zebra e o alce felizardo, não habitam em comum com o leopardo, o leão e o tigre_debengala. O macaco faz tudo, mas não fala [...]. Tem o búfalo aspecto de grandeza, o boi manso e o puma tão valente, cada um de uma espécie diferente, tudo isso é obra da natureza [...]. O réptil de aspecto esquisito, o pequeno tamanho do mosquito, a tromba prênsil do elefante, a saliva incolor do ruminante, a mosca nociva e indefesa, a cobra que ataca de surpresa, aplicar o veneno é seu mister, de uma vez mata trinta se puder, mas isso é coisa da natureza [...]. O morcego_com o rato bastante se parece, nas cavernas escuras sobe e desce, sugar sangue dos outros é seu emprego. Às noites escuras tem apego, asqueroso ele é tenho certeza. Tem na vista sintoma de fraqueza, porém o seu ouvido é muito fino e tem um sonar aparelho pequenino que lhe deu o autor da natureza [...]. A formiga pequenina, fidalgal inimiga da lavoura. No trabalho aplicada professora, um exemplo de pura disciplina. Através das antenas se combina, nos celeiros alheios faz limpeza. Formigueiro é a sua fortaleza onde cada uma delas tem emprego, uma entra outra sai não tem sossego, isso é coisa da santa natureza. A aranha pequena, tão arguta, de finíssimos fios faz a teia [...]. Labirinto intrincado ela executa. Seu trabalho é bordado em qualquer mesa. Quem pensar destruir-lhe a fortaleza perderá de uma vez toda a esperança. Sua rede é autêntica segurança, operária das mãos da natureza [...]. O inseto do sono tsé-tsé [...]. A feiúra real do 
caboré, no pavão é enorme a boniteza. Tem o lince visão e agudeza e o cachorro finíssima audição, vigilante mal pago do patrão, isso é coisa da santa natureza? A cigarra cantante dialoga através do seu canto intermitente [...]. Sua música sinônimo de tristeza, patativa da seca é o seu nome. Se deixar de cantar morre de fome, mas isso a gente sabe que é da natureza.

A ausência de voz-construto de resistência observada quando se analisa o conteúdo das duas últimas obras, principalmente em Natureza, não desclassifica tais músicas como instrumentos conscientizadores da luta pela preservação ambiental. Ao contrário, servem elas como importante veículo de retratação de ambientes naturais pertencentes a diferentes ecossistemas que devem ser enaltecidos e usados como elemento disseminador da luta de movimentos sociais em prol da preservação da fauna terrestre.

Fica, assim, ativado o sinal de alerta àqueles que perseguem vidas da fauna e flora, recursos e paisagens naturais. Os autores de Natureza avisam: quem pensar em destruir a fortaleza de tão rica biodiversidade, perderá de uma vez toda a esperança, pois a rede vital biodiversa é de autêntica segurança, operária das mãos da natureza.

\section{Conclusão}

O estudo usou a poesia contida em parte das obras da MPB-NE, apresentando o conteúdo poético-ecológico de cinco músicas de autores nordestinos. Como conclusão, sugere-se que tal acervo possa ser usado, seguindo Escobar (1998), como instrumento de atuação concreta por parte de movimentos ambientalistas do Brasil. As vozes da resistência à degradação ambiental, com foco na fauna, flora e ambientes naturais, e entoadas por compositores-cantadores do Nordeste, revestem-se de importância ímpar no que diz respeito à apropriação e conservação de nossa biodiversidade e à atuação de movimentos sociais de resistência a ações degradadoras. Como pertinentemente colocado em dois artigos da revista Do or Die (1996 e 1999), a restauração do meio ambiente é atividade providencial que engloba novo paradigma ao colocar o ser humano como criador e reparador da natureza, e não como ente que só destrói.

Vale ressaltar que a interação teoria-prática do presente estudo não é perfeita, visto que parte substancial das contribuições teóricas usadas nas seções 1 e 2 dá ênfase ora aos moldes alienígenas de comportamento impostos pelo elemento invasor às comunidades locais, ora à atuação de movimentos sociais de resistência à degradação ambiental. Tal spectrum não habilita o uso prático aqui feito da poesia ecológica da MPB-NE como movimento ambientalista de resistência per si. Mas isso não invalida o objetivo maior do artigo, que é alertar para a possibilidade e pertinência do uso dessa importante riqueza poético-cultural nordestina como instrumento disseminador da luta contra a degradação ambiental na atuação concreta por parte de movimentos ambientalistas do Brasil. Apesar de no país não existir explicitamente movimentos socioculturais localizados e focados, em relação à resistência à degradação ambiental e encampados por compositores-cantadores-letristas do Nordeste, o conteúdo de resistência dessas vozes é imenso e de grande potencial de penetração na esfera sociopolítica. Assim, em sintonia com o objetivo do presente artigo, movimentos sociais ambientalistas no Brasil podem e devem utilizar o acervo de vozes poético-ecológicas da MPB-NE como instrumento de intensificação harmoniosa na atuação concreta em defesa da preservação da biodiversidade.

Em referência às perspectivas abertas a trabalhos futuros pode-se dizer que estudos alternativos, por exemplo, sobre vozes da resistência à degradação das condições humanas locais, inclusive contemplando resistência à imposição de pretensas modernidades advindas do exterior, podem ser conduzidos usando-se metodologia idêntica a aqui utilizada. Melo (1982), por exemplo, refere-se a tal imposição de modernidade, que, em resistência a ela, fê-lo errante e violeiro, entoando que "[...] pro cantador e violeiro só há três coisas nesse mundo vão: amor, forria, viola [...] nunca dinheiro [...]". Assim, em relação à resistência que coloca no cerne da análise a degradação da condição humana local impetrada por elemento estranho, pode-se vislumbrar o uso da voz de certeza de luta entoada pelo poeta potiguar Silvestre (1984): “[...] Só é cantador quem traz no peito o cheiro e a cor de sua terra, a marca de sangue de seus mortos e a certeza de luta de seus vivos [...]". 


\section{Referências}

AVELINO, E.; JATOBÁ, A: Água. In: AVELINO, E. Quê que tu tem canário (Vinil). Rio de Janeiro: Estúdios de Invenções da Transamérica, 1981.

DALLMAYR, F. Global development? alternatives voices from Delhi. Alternatives, v. 21, n. 2, p. 259-279, April-June, 1996.

DIAS, S: Canção da floresta. In: LOPES, R. Donos do Brasil (CD). Rio de Janeiro: Indie Records, 2004.

DO OR DIE - Voices from the Ecological Resistance. Environmental restoration may be the art form of the twentyfirst century. Issue 5, p. 72-73, 1996.

. Take a sad song and make it better? ecological restoration in the UK. Issue 8, p. 159-163, 1999.

EDWARDS, M. The irrelevance of development studies. Third world quarterly. II, 1, January, 1989.

ESCOBAR, A. Reflections on development: grassroots approaches and alternative politics in the third world. Futures, v. 24, n. 5 , p. 411-436, 1992.

. Encountering development: the making and unmaking of the third world. Princeton: Princeton University Press, 1995.

. Whose knowledge, whose nature? biodiversity, conservation, and the political ecology of social movements.

Journal of political ecology, v. 5, p. 53-81, 1998.

FARIAS, V: Saga da Amazônia. In: MELO, E.; AZEVEDO, G.; FARIAS, V.; AVELINO, E. Cantoria (Vinil). Rio de Janeiro: Kuarup Produções Ltda., 1984.

GASPER, D. Culture and development ethics: needs, women's rights, and western theories. Development and change, v. 27, p. 627-661, 1996.

JATOBÁ, A: Matança. In: MELO, E., AZEVEDO, G., FARIAS, V. e AVELINO, E. Cantoria (Vinil). Rio de Janeiro: Kuarup Produções Ltda., 1984.

MELO, E: O Violeiro. In: MELO, E. Das Barrancas do Rio Gavião (Vinil). Rio de Janeiro: Polygram, 1982.

MUSE (USA) - Musicians United to Sustain the Environment. Disponível em: $<$ http://www.musemusic.org/> Acesso em 26 set. 2007.

PETERSON, G. Political ecology and ecological resilience: an integration of human and ecological dynamics. Ecological economics, v. 35, p. 323-336, 2000.

POSTEL, S. Carrying capacity: earth bottom line. In: Worldwatch Institute. State of the World. 1994.

SILVESTRE, F: Cantoria. In: MELO, E.; AZEVEDO, G.; FARIAS, V.; AVELINO, E. Cantoria (Vinil). Rio de Janeiro: Kuarup Produções Ltda., 1984.

VILlanOVA, I.; AVELINO, E: Natureza. In: AVELINO, E. Mutirão da vida (Vinil). Rio de Janeiro: Kuarup Produções Ltda., 1984. 